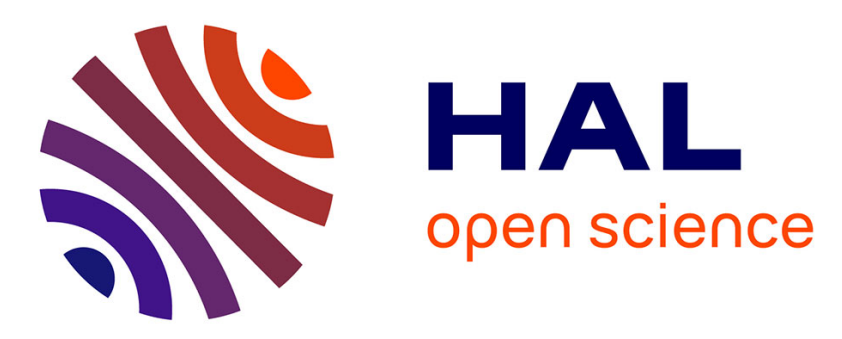

\title{
Sub-microliter microwave dielectric spectroscopy for identification and quantification of carbohydrates in aqueous solution
}

François Artis, David Dubuc, J-J Fournié, M Poupot, Katia Grenier

\section{- To cite this version:}

François Artis, David Dubuc, J-J Fournié, M Poupot, Katia Grenier. Sub-microliter microwave dielectric spectroscopy for identification and quantification of carbohydrates in aqueous solution. IEEE Topical Conference on Biomedical Wireless Technologies, Networks, and Sensing Systems (BioWireleSS 2015), Jan 2015, San Diego, United States. 5p., 10.1109/BIOWIRELESS.2015.7152125 . hal01951678

\author{
HAL Id: hal-01951678 \\ https: / hal.laas.fr/hal-01951678
}

Submitted on 11 Dec 2018

HAL is a multi-disciplinary open access archive for the deposit and dissemination of scientific research documents, whether they are published or not. The documents may come from teaching and research institutions in France or abroad, or from public or private research centers.
L'archive ouverte pluridisciplinaire HAL, est destinée au dépôt et à la diffusion de documents scientifiques de niveau recherche, publiés ou non, émanant des établissements d'enseignement et de recherche français ou étrangers, des laboratoires publics ou privés. 


\title{
Sub-microliter microwave dielectric spectroscopy for identification and quantification of carbohydrates in aqueous solution
}

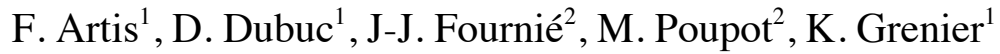 \\ ${ }^{1}$ LAAS-CNRS, 7. Av. du Colonel Roche, F-31031 Toulouse \\ ${ }^{2}$ CRCT, INSERM, 2. Av. Hubert Curien, Oncopole, F-31037 Toulouse cedex 1
}

\begin{abstract}
This paper presents the technique and associated miniature RF biosensor dedicated to the microwave dielectric spectroscopy of carbohydrates in aqueous solution. Small amounts of liquid in the range of microliter are required. This sensor includes an area for electromagnetic field analysis that operates in the near field, while a microfluidic channel allows precisely bringing and locating the liquid solution to be studied on the sensing zone. Different carbohydrates were measured from $40 \mathrm{MHz}$ to 40 $\mathrm{GHz}$ with relevant concentrations for biologists and chemists. Derived from the extracted complex relative permittivity of the examined liquids, this paper shows that each biomolecules type exhibits a specific dielectric signature, which allows their identification and quantification.
\end{abstract}

Index Terms - Microwave, coplanar waveguide, biosensor, dielectric spectroscopy, carbohydrates.

\section{INTRODUCTION}

Many applicative fields such as chemistry, pharmacology, biology, and others require a precise detection and quantification of biomolecules. For instance, measuring the level of glucose in the blood constitutes a flagship application. This data is absolutely mandatory for any diabetic person [1] and should be obtained regularly.

Among the possible methods of miniature biodetections (optical, mechanical, chemical ones), the microwave techniques are particularly attractive due to, on one hand their direct measurement ability (it does not result from molecular reactions) and on the other hand the fact that they do not require bio-functionalization [2]-[4]. Among these solutions, the microwave dielectric spectroscopy of liquids provides access to a wealth of information on the studied medium [5]-[6].

This paper aims therefore to demonstrate that the microwave dielectric spectroscopy technique applied to biomolecules in aqueous solution, and especially carbohydrates, is possible at concentrations and volumes of interest for biologists and chemists and it provides important levels of sensitivity and specificity of detection.
After a short description of the microwave biosensor given in section II, section III presents the evaluation of different carbohydrates in aqueous solution.

\section{DESCRIPTION OF THE MICROWAVE BIOSENSOR}

Fig. 1 presents the photography of the microwave biosensor used to characterize different biomolecules in aqueous solutions.

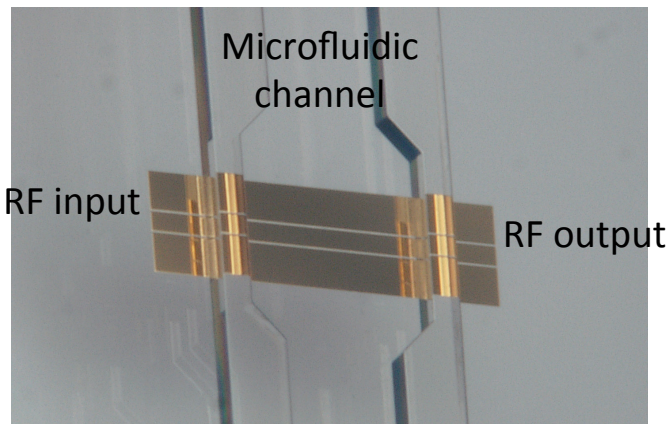

Fig. 1. Photography of the microwave biosensor, which is composed of a coplanar line with a microfluidic channel perpendicularly placed on top.

It is comprised of a coplanar line placed on a quartz wafer, and composed of a flash of titanium and a gold layer of $0.3 \mu \mathrm{m}$ thick. A microfluidic channel is located perpendicularly. This channel, which is realized in the elastomer PDMS, has been obtained from a silicon mold. It allows to precisely localize the tested liquid on the sensing area with a controlled volume lower than a microliter. This sensor has previously been validated with various reference liquids, such as deionized water, ethanol, and also with various biological fluids and cells suspensions [7].

\section{EVALUATION OF THE RF BIOSENSOR WITH CARBOHYDRATES IN AQUEOUS SOLUTION}

A method has been established in [6] to extract the complex relative permittivity of a liquid medium in such a structure. It has been applied to different molecules in 
aqueous solution, and especially on carbohydrates, in order to determine if dielectric spectroscopy could provide differentiation of the same family of molecules. Various carbohydrates: glucose, maltose, rhamnose, sucrose, heparin, and glucitol, have therefore been investigated.

Fig. 2 presents the real part (blue and green colors) and imaginary (red-yellow colors) relative permittivity of glucose and maltose in aqueous solution at a concentration of $100 \mathrm{mg} / \mathrm{ml}$, which is compatible with those conventionally used by biologists. It also includes deionized water (DI-water) spectra versus frequency, from $40 \mathrm{MHz}$ to $40 \mathrm{GHz}$.

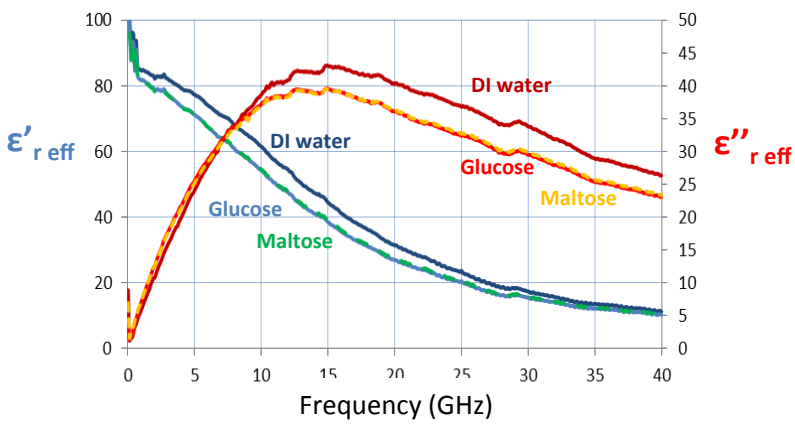

Fig. 2. Real (in blue and green) and imaginary (in red and yellow) parts of the complex effective permittivity of glucose and maltose in aqueous solution, as well as de-ionized water (in dark blue and red).

In a first observation, glucose and maltose spectra may not be discriminated. Only their dielectric spectra compare to DI-water ones may be distinguished and considered significantly different.

To enable the discrimination of carbohydrates in aqueous solution with microwave dielectric spectroscopy, the dielectric contrasts compare to DI-water, which serves as a host medium to the molecules, have been calculated using Equations 1 and 2. Equation 1 and 2 corresponds to the real and imaginary parts of complex relative permittivity respectively.

$$
\begin{aligned}
& \Delta \varepsilon^{\prime}=\varepsilon_{\text {ose }}^{\prime}-\varepsilon_{\text {DI-water }}^{\prime} \\
& \Delta \varepsilon^{\prime \prime}=\varepsilon_{\text {ose }}^{\prime \prime}-\varepsilon_{\text {DI-water }}^{\prime \prime}
\end{aligned}
$$

The permittivity contrasts are indicated in Fig. 3 for glucose and maltose. Both may now be discriminated as standard deviation has been evaluated to be lower than 0.15 . This is also the case of the other oses.

The effect of concentration has been evaluated for all investigated sugars. Fig. 4 presents the two relative permittivity contrasts $\Delta \varepsilon^{\prime}$ and $\Delta \varepsilon^{\prime \prime}$ at $20 \mathrm{GHz}$ for glucose with concentrations in aqueous solution ranging from 0.8 to $100 \mathrm{mg} / \mathrm{l}$.

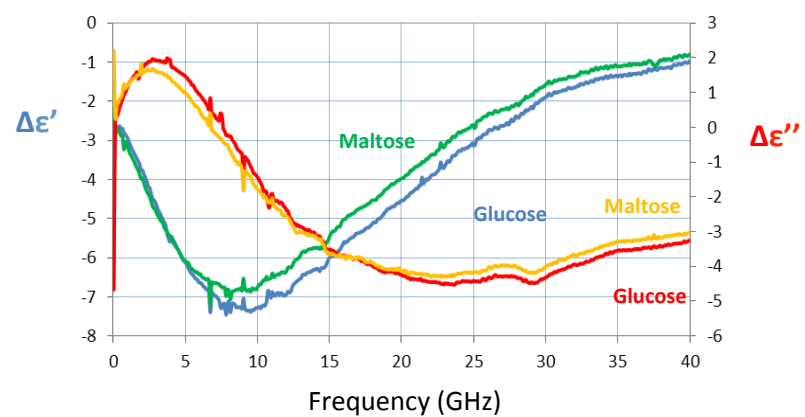

Fig. 3. Relative permittivity contrasts of both real and imaginary parts, for glucose and maltose in aqueous solution.

The origin $(0,0)$ corresponds to the host medium, deionized water in the case of these biomolecules. Both parameters present a linear variation versus concentration.

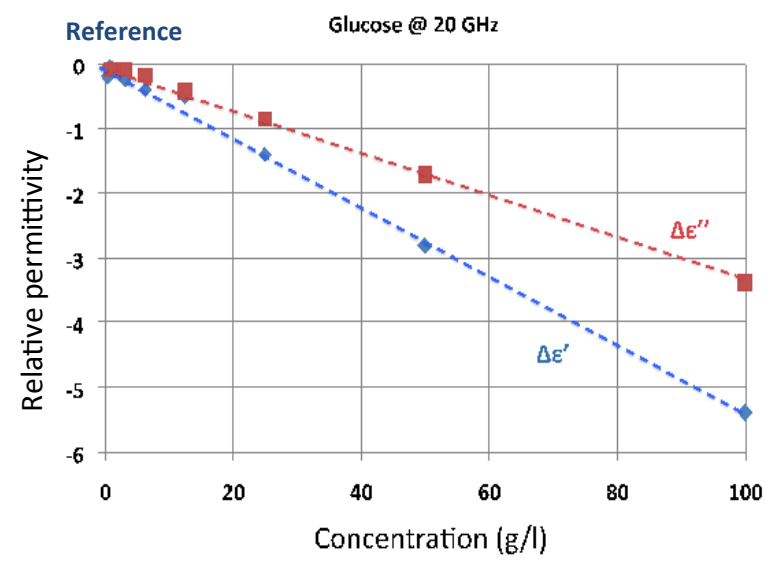

Fig. 4. Linear variations of the relative dielectric contrasts of glucose at $20 \mathrm{GHz}$ versus concentration ranging from 0.8 to 100 $\mathrm{mg} / \mathrm{ml}$.

Proportionality between the complex permittivity contrast and the concentration of biomolecules in solution is consequently achieved.

The analysis of the results for the other types of carbohydrates shows that the proportionality coefficients are all different and specific to the biomolecule. Therefore, a molecule presents, based on its concentration in liquid solution, a specific slope in the complex plane $\left(\Delta \varepsilon^{\prime \prime}, \Delta \varepsilon^{\prime}\right)$, as shown in Fig. 5 for glucose at the frequency of $20 \mathrm{GHz}$. 


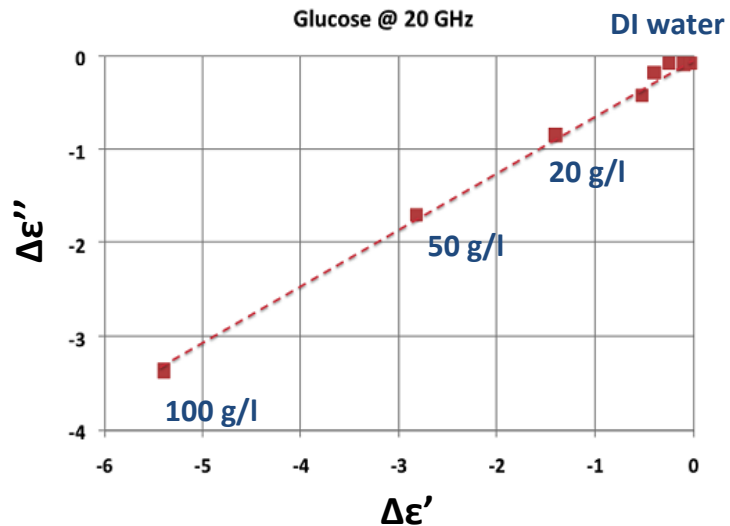

Fig. 5. Complex relative permittivity contrasts plot of glucose at $20 \mathrm{GHz}$ for different concentrations (0 to $100 \mathrm{mg} / \mathrm{ml})$.

On this figure, the different points correspond to different concentrations of glucose: points move away from the origin when the glucose concentration increases.

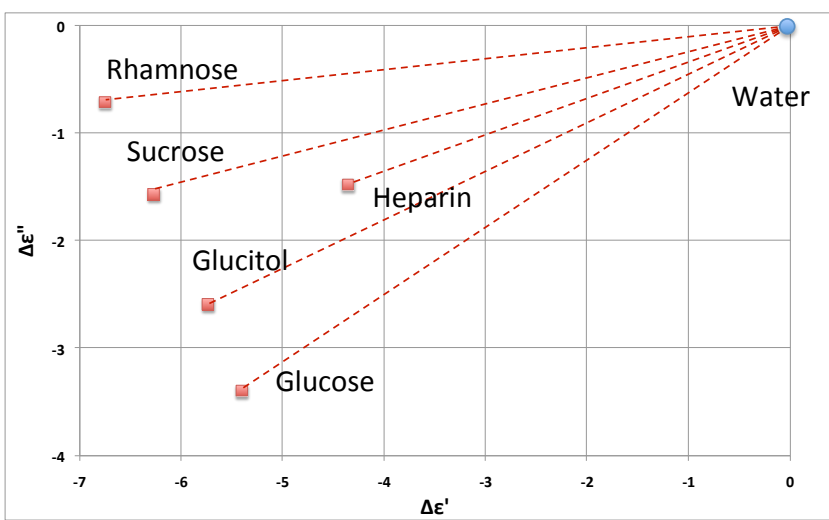

Fig. 6. Discrimination of oses in aqueous solution, depending on their dielectric characteristics at $20 \mathrm{GHz}$.

Fig. 6 summarizes the results obtained at $20 \mathrm{GHz}$ in the complex plane of the permittivity $\left(\Delta \varepsilon^{\prime \prime}, \Delta \varepsilon\right.$ ') for the different carbohydrates. Since water is used as reference, it defines the origin of the plan. All sugars (measured with the same concentration) is located at different places in the plot and may be unambiguously discriminated.

This possible discrimination is related to the phenomenon of relaxation of polar molecules, which depends on the physical characteristics of the molecules. The dielectric spectra of oses exhibit therefore a microwave signature, which enables their identification and discrimination.

\section{CONCLUSIONS}

A biosensor dedicated to the microwave dielectric spectroscopy has been developed and evaluated in the characterization of biomolecules in aqueous solution. The developed technique allows using very small quantities of liquids, below the microliter, and provides access to a specific dielectric signature, which enables the molecule's identification and concentration evaluation. Further investigations should be done to assess the limit of microwave dielectric spectroscopy in terms of biomolecules identification.

This technique already offers important perspectives for applications, particularly in the development of future labon-chip where miniature, noninvasive, fast sensing, in a liquid medium, and at low volume, is a challenge.

\section{ACKNOWLEDGEMENT}

The authors wish to acknowledge the financial support of the RITC Foundation, as well as the RENATCH network for supporting the microfabrication of the device in the LAAS-CNRS clean room.

\section{REFERENCES}

[1] http://fr.wikipedia.org/wiki/Diabète

[2] D. J. Rowe, A. Porch et al. « Integrated Microwave Resonant Device for Dielectric Analysis of Microfluidic Systems », IEEE EuMW2011

[3] A. I. Gubin, A. A. Barannik et.al., "Whispering-Gallery Mode Resonator Technique for Characterization of Small Volumes of Biochemical Liquids in Microfluidic Channel", IEEE EuMW2011

[4] M. Hofmann, G. Fischer, R. Weigel, D. Kissinger, "Microwave-based non invasive concentration measurements for biomedical applications," IEEE T-MTT, Vol. 61, n 5, pp. 2195-2204, May 2013

[5] F. Kremer, « Broadband dielectric spectroscopy », Springer 2003

[6] K. Fuchs, U. Kaatze, "Molecular dynamics of carbohydrate aqueous solutions. Dielectric relaxation as a function of glucose and fructose concentration," J. Phys. Chem. B, 105, pp. 2036-2042, 2001.

[7] K. Grenier, D. Dubuc, et al., « Integrated Broadband Microwave and Microfluidic Sensor Dedicated to Bioengineering », IEEE T-MTT, pp. 3246-3253, Dec. 2009. 